\title{
STUDENTS' ATTITUDES TOWARD STATISTICS ACROSS THE DISCIPLINES: A MIXED-METHODS APPROACH
}

\author{
JAMES D. GRIFFITH \\ Shippensburg University of Pennsylvania \\ jdgrif@ship.edu \\ LEA T. ADAMS \\ Shippensburg University of Pennsylvania \\ ltadam@ship.edu \\ LUCY L. GU \\ Shippensburg University of Pennsylvania \\ lg3282@ship.edu \\ CHRISTIAN L. HART \\ Texas Woman's University \\ chart2@twu.edu \\ PENNEY NICHOLS-WHITEHEAD \\ Grand Valley State University \\ nicholpe@gvsu.edu
}

\begin{abstract}
Students' attitudes toward statistics were investigated using a mixed-methods approach including a discovery-oriented qualitative methodology among 684 undergraduate students across business, criminal justice, and psychology majors where at least one course in statistics was required. Students were asked about their attitudes toward statistics and the reasons for their attitudes. Five categories resulted for those with positive and negative attitudes and were separated on the basis of discipline. Approximately $63 \%$ of students indicated a positive attitude toward statistics. Business majors were most positive and were more likely to believe statistics would be used in their future career. Multiple methodological approaches have now provided data on the various domains of attitudes toward statistics and those implications are discussed.
\end{abstract}

Keywords: Statistics education research; Statistics attitudes; Fear of statistics

\section{INTRODUCTION}

Statistics is a methodological course that is required by a large number of undergraduate majors and focuses on the conceptual ideas and tools used to work with data. The statistics course often represents one of the few required courses in many social science and education oriented majors and serves as a foundation for understanding how research is conducted. Ridgway, Nicholson, and McCusker (2007) noted that statistics is the one central science used in social science and education. In fact, it is challenging to consider a discipline in which some level of statistics is not used.

However, most students view a required statistics course as a formidable obstacle (Dunn, 2000; Laher, Israel, \& Pitman, 2007). Students are ultimately concerned with the successful completion of the statistics course as they aim to fulfill the necessary requirements of their major. Prior research has identified cognitive and demographic factors related to student performance in statistics courses including gender, prior knowledge, mathematical ability, spatial ability, and pedagogical approaches (e.g., Derry, Levin, Osana, Jones, \& Peterson, 2000; Elmore \& Vasu, 1980, 1986; Feinberg \&

Statistics Education Research Journal, 11(2), 45-56, http://www.stat.auckland.ac.nz/serj

C International Association for Statistical Education (IASE/ISI), November, 2012 
Halperin, 1978; Schram, 1996; Schutz, Drogosz, White, \& Distefano, 1998). In addition to demographic, cognitive, and pedagogical factors, affective and attitudinal factors among students should also be taken into consideration by instructors teaching statistics (Mills, 2004; Mulhern \& Wylie, 2004; Onwuegbuzie, 2000; Onwuegbuzie \& Seaman, 1995). In fact, some scholars (Blalock, 1987; Garfield \& Ben-Zvi, 2007) have suggested that instructors should focus on the value of statistics in order to foster more positive attitudes toward statistics and should attempt to reduce the fear of statistics as an initial step of instruction.

Interestingly, most studies investigating attitudes toward statistics have not examined differences across disciplines or majors. Although most social science and education majors are typically required to take a statistics course (Ridgway et al., 2007), there is little consistency in terms of who teaches the course. In other words, it may be taught by a departmental methodologist or by an instructor in the mathematics or statistics department depending on the arrangement at the particular department. In addition to education and the social sciences, there are other majors (e.g., business) that are required to take a course in statistics and it should be of interest to determine who best to teach statistics courses to these non-science majors. Some researchers who have investigated attitudes toward statistics within one discipline have recommended comparison across majors (e.g., Coetzee \& van der Merwe, 2010). Mij (2009) examined differences within a business school. Specifically, comparisons were made between students from accounting, taxation, and marketing. It was reported that taxation majors had more negative attitudes toward statistics than the other two groups. Because of the importance of statistics as a required course across many disciplines and the limited amount of research comparing different majors, such comparisons may yield interesting results and show distinct patterns across various disciplines which could be used to better tailor statistics courses for students of a given major.

Student attitudes toward statistics are important because they may be related to the learning process. In fact, studies have reported that attitudes toward statistics were related to the development of statistical thinking skills, the degree to which statistics will be used outside of the classroom, the likelihood of enrolling in future statistics related courses, persistence, achievement, and the general climate in class (Gal, Ginsburg, \& Schau, 1997; Hilton, Schau, \& Olsen, 2004). There is additional research supporting the notion that negative attitudes toward statistics are related to worse performance in class (e.g., Waters, Martelli, Zakrajsek, \& Popovich, 1988). Teaching statistics may be regarded as a complicated endeavor because many factors in addition to the pedagogical approach must be taken into consideration. Thus, there is ample evidence that among the many factors to take into consideration when teaching a course in statistics, attitudes toward the course should certainly not be ignored.

If an instructor is to take attitudes toward statistics into consideration when teaching, there must be psychometrically sound ways to measure those attitudes. The measurement of attitudes toward statistics has evolved since it was first investigated. There have been three primary inventories used in the majority of investigations examining this topic. The first instrument was developed by Roberts and Bilderback (1980) which was a 33-item unidimensional measure referred to as the Statistics Attitude Survey (SAS). The development of the SAS was largely based on the work of Aiken (Aiken, 1970; Aiken, 1976; Aiken \& Dreger, 1961) who suggested that there were affective instruments that were capable of augmenting cognitive measures of mathematics achievement. The second assessment was the Attitudes Toward Statistics (ATS) scale developed by Wise (1985) which had two subscales consisting of the attitude toward the field of statistics and the attitude toward the course. The ATS was created in an effort to improve on the SAS by focusing on items measuring attitudes, rather than student success. The most recent assessment instrument is the Survey of Attitudes Toward Statistics scale (SATS-28; Schau, 1992; Schau, Stevens, Dauphinee, \& Del Vecchio, 1995) which initially reported four subscales consisting of affect, cognitive competence, value, and difficulty. The scale was later expanded to include two more dimensions of effort and interest (SATS-36; Schau, 2003). Both versions of the SATS have solid theoretical underpinnings as they are based on a number of popular theories including expectancy value, attribution, social cognition, and goal theories (e.g., Atkinson, 1957; Bandura, 1977; Maehr, 1984; Weiner, 1979). All of the scales have made valuable contributions in providing a better understanding of students' attitudes toward statistics. The development and use of these inventories have mostly used quantitative methodologies. 
Sophisticated models have been tested in an effort to explain the relationships between attitudes, skills, and performance (e.g., Harlow, Burkholder, \& Morrow, 2002; Tempelaar, Van Der Loeff, \& Gijselaers, 2007). Despite years of study on attitudes toward statistics, the domains of those attitudes are not yet fully understood and some of those domains may have changed over time because of the evolving modalities of course delivery. For example, the use of technology (e.g., statistical programs such as SPSS and SAS) may have been emphasized more over time, and hand calculations using formulas and tables to interpret significant findings may be used less frequently. Furthermore, some statistics classes are now offered online. These are just two factors that might be important in assessing student attitudes toward statistics because of the increasing reliance on technology in teaching the course. Thus, perhaps some dimension of technology as related to a statistics course may be worth examining. Another approach to studying attitudes is to incorporate both qualitative and quantitative methodologies in the same design. A mixed-methods research design was used for this study in order to describe the attitudes from the perspective of the student using a qualitative approach described by Vidich and Lyman (1994) along with a series of chi-square tests to examine relationships between attitudes and major. The primary interest of this investigation was to use a mixed-methods approach to determine the domains associated with both positive and negative attitudes across students from three different majors.

\section{METHOD}

\subsection{PARTICIPANTS}

A total of 684 undergraduate participants took part in the study. There were $416(61 \%)$ females and $268(39 \%)$ males in the study. For class standing, $188(28 \%)$ were Freshmen, $317(46 \%)$ were Sophomores, 133 (19\%) were Juniors, $46(6.7 \%)$ were Seniors. The college participants were selected from three different majors which included 207 (30\%) in business, $196(29 \%)$ in criminal justice, and $281(41 \%)$ in psychology. The age range for the college participants in this study was 18-48 years of age, with a mean of 21. Participants were recruited from two universities in the United States during a two year period. Both institutions were master's granting universities. Participants were required to be enrolled in a statistics course at the undergraduate level and be a business, criminal justice, or psychology major. All of the courses were taught by instructors from the respective discipline. The size of the classes ranged from 22 to 45 students. The courses were taught by six instructors (all male), one from each discipline from each university. There were no substantial differences in the gender distributions across disciplines or universities among participants.

\subsection{INSTRUMENTS}

Participants in the study were asked two questions. They were first asked, "In general, is your attitude toward statistics positive or negative?" This question was counterbalanced such that half of the participants were asked the question, "In general, is your attitude toward statistics negative or positive?" Within each classroom where the data were collected, half of the participants were given the first version and the other half the second version, thus they were systematically distributed within classrooms. Participants were forced to choose either a positive or negative attitude. This was done because of the possibility of a substantial number of respondents being neutral, which could be viewed as not having an attitude based on the rudimentary categorization that was used. This dichotomization of an attitude toward statistics was meant to serve as a foundation to determine the most basic distinction between individuals in order to examine possible reasons for those attitudes. The second question aimed to determine the dimensions of those attitudes and asked, "What are the reasons for your attitude toward statistics?" Participants provided responses in a written format.

\subsection{PROCEDURE}

Data were collected approximately eight weeks into the semester so that each student had some exposure to a statistics course and all participants had taken at least one exam. All participants were administered the questions in a classroom setting by a research assistant at each university. One 
undergraduate research assistant at each university collected the data at their respective institution. Participants were assured that their responses were anonymous because their name did not appear on their response sheet and the instructor of each class did not see any of the responses. Participation was voluntary and students received extra credit for their involvement. Participants were instructed that they had to indicate that they either had a positive or negative attitude toward statistics and to provide the reasons for that attitude.

\subsection{QUALITATIVE DATA ANALYSES}

This study used a mixed-methods design. The first phase included a discovery-oriented qualitative methodology consisting of two parts. Grounded theory data analysis techniques (Strauss \& Corbin, 1998) and consensual qualitative research techniques (Hill, Thompson, \& Williams, 1997) were combined to form an integrative approach designed to address the factors associated with positive and negative attitudes toward statistics. The first step was to develop categories that emerged from participant responses. The second step involved an analysis of the frequency of responses across those categories for both the positive and negative groups along with examining the responses across the three majors. The research team consisted of eight judges, two auditors, and a research consultant; all of whom were from a university where the data were not collected. All eight judges were advanced psychology students; there were four females and four males. The auditors consisted of psychology graduate students; one female and one male. The research consultant was a male psychology faculty member. No members of the research team were involved in the data collection.

The first step was the development of a coding scheme. Responses were separated on the basis of participants indicating either a positive or negative attitude. Next, 100 positive and 100 negative responses were randomly selected and given to four judges who were randomly selected. The judges independently coded the written responses to each of the questions (i.e., identified concepts). Each of the judges began reviewing the data by engaging in a line-by-line analysis (Straus \& Corbin, 1998). There were cases where individual responses were commonly assigned to multiple codes as some responses contained multiple concepts. Each judge was randomly assigned to form a dyad with another judge to compare, contrast, and refine the codes. Then, both dyads of judges met with the research consultant to generate an initial coding system which consisted of a list of all codes that emerged from the randomly selected responses. The judges discussed the codes and arrived at consensual agreement about the most appropriate codes that captured the essences of the data. Thus, the coding scheme served as a conceptual framework to organize the data (Miles \& Huberman, 1994).

After the coding scheme was developed, analysis of all of the data was initiated. There was considerable variability in the responses as the shortest response consisted of two words and the longest consisted of 174 words. A second set of four judges (i.e., not used in the initial step) was given all responses. Each judge coded each response assigning codes to individual responses, then was randomly assigned to form a dyad with another judge in order to reach consensus about the coding. Judges coded the data using the existing coding scheme while expanding the coding scheme to incorporate the additional voices of the participants from the entire sample. This resulted in the addition of one category in the negative attitude domain. All four judges met with the research consultant to discuss and reach consensus about the coding. The judges collapsed, revised, or discarded their codes into overarching categories using the constant comparative method (Strauss \& Corbin, 1998) and a consensual decision-making process (Hill et al., 1997). The categories represented superordinate themes that cut across the codes developed. These findings were then presented to the auditors. The auditors noted inconsistencies (e.g., same response being assigned different codes) and aspects of the coding system that lacked clarity (e.g., meaning of a particular code). The four judges then began another iteration of refining the categories, making consensual decisions in response to the auditor's feedback, and making revisions to the codes assigned and to the coding scheme. The auditors served as valuable means of triangulating the data analytic procedure of the four judges throughout the research process (Hill et al.; Patton 1990) and were used to increase the validity of the study results (Guba \& Lincoln, 1989). The auditors also assisted in reaching consensus with the judges that data saturation had been achieved (Morrow \& Smith, 2000; Patton, 1990) after the 684 cases were analyzed. Through the process of developing the categories, the research team was able to ensure that no new themes emerged from the data and that the categories were representative 
of the experiences of all the participants in the study. Thus, the discovery-oriented data analysis approach yielded a final conceptual network of reasons why participants had positive or negative attitudes of statistics.

\section{RESULTS}

After categories were rigorously devised and the frequencies of responses across categories were totaled, examination of the data could occur. Prior to that analysis, a chi-square test was conducted to determine whether the counterbalancing of the words "positive" and "negative" was related to participant responses. There were no significant differences found with regard to order and attitudes. The next step in the analysis plan examined whether there were differences across majors with regard to having a positive or negative attitude toward a statistics course. Table 1 provides the frequencies and percentages of the responses. Overall, approximately three out of every five students indicated that they had a positive attitude toward statistics. A chi-square test $\chi^{2}(2, n=684)=8.43, p<.05$, indicated there was a relationship between major and general attitudes toward statistics. A Bonferroni correction was used to examine differences between majors; for an overall $\alpha=0.05$ we require individual $p$-values below $0.05 / 3=0.017$. Business majors had more positive attitudes compared to criminal justice majors $(z=2.82, p<.017, \alpha=0.05)$ and there was a trend $(z=2.25,0.017<p<.033$, $\alpha=0.10$ ) that did not meet significance but is suggestive of a relationship with business majors also having more positive attitudes than psychology majors. These findings provide evidence that majors differ with regard to general attitudes toward statistics, but what might account for those differences was the question that was further examined by taking a closer look at the categories within each dimension of attitude (i.e., positive and negative).

Table 1. Frequencies and percentages of positive and negative attitudes by majors

\begin{tabular}{lccc}
\hline \multirow{3}{*}{ Major } & \multicolumn{3}{c}{ Attitude } \\
\cline { 2 - 4 } & Positive & Negative & Total \\
& $n(\%)$ & $n(\%)$ & $n$ \\
\hline Business & $146(70 \%)$ & $61(30 \%)$ & 207 \\
Criminal Justice & $112(57 \%)$ & $84(43 \%)$ & 196 \\
Psychology & $171(61 \%)$ & $110(39 \%)$ & 281 \\
\hline Total & $429(63 \%)$ & $255(37 \%)$ & 684 \\
\hline
\end{tabular}

\subsection{POSITIVE ATTITUDE CATEGORIES}

There were $63 \%(n=429)$ of students across majors who had a positive attitude toward statistics. For those students with a positive attitude, the qualitative data analysis yielded five categories of responses which represented reasons for the attitude from the perspective of the student. The response categories, when collapsed across majors in descending order, included: use in future career, necessary for graduate school, professor, like math, and challenging course. See Table 2 for the frequencies and percentages of responses across majors. It should be noted that participants could have indicated several categories within a question, thus the frequencies add up to more than the sample size and percentages to more than $100 \%$. A series of five chi-square tests, one for each category, were conducted, to determine whether there was a relationship between major and the response category. A Bonferroni correction was used to account for the multiple chi-square tests. The analyses yielded significant findings for use in future career across majors $\left(\chi^{2}(2, n=290)=17.92, p<\right.$ $.01)$. A Bonferroni correction was again used to examine the pairwise comparisons which showed that business majors provided more frequent responses compared to criminal justice $(z=3.26, p<.017)$ and to psychology majors $(z=4.26, p<.017)$. In addition, there were significant findings for graduate school across majors $\left(\chi^{2}(2, n=283)=11.41, p<.01\right)$, with psychology majors providing more frequent responses compared to business $(z=2.90, p<.017)$ and to criminal justice majors $(z=$ $2.93, p<.017)$. 
Approximately two-thirds of all majors with a positive attitude toward statistics indicated that it would be useful in their future career (i.e., 68\%) and it is important for graduate school (i.e., 66\%). Based on the data, business majors seem to have a better understanding of the importance of statistics in their future career whereas psychology majors tend to believe that statistics is important for graduate school. It may be the case that those studying business have examples that are directly transferrable to a real world setting in which the student may soon work. In contrast, it may be possible that criminal justice and psychology students choose fields that are more oriented toward "direct services" and may have difficulty understanding the usage of statistics in the specific field they may pursue. With regard to graduate school, psychology majors may have limited employment opportunities that are viewed favorably with a bachelor's degree as many students may plan to attend graduate school in order to have more employment options. Business and criminal justice majors, however, may have more employment opportunities and career advancement opportunities with a bachelor's degree. Many students provided responses with several categories represented as the following examples show.

Table 2. Frequencies and percentages of responses for those with a positive attitude toward statistics by major

\begin{tabular}{|c|c|c|c|c|c|c|c|c|}
\hline \multirow{3}{*}{ Category } & \multicolumn{8}{|c|}{ Major } \\
\hline & \multicolumn{2}{|c|}{$\begin{array}{c}\text { Business } \\
(n=146)\end{array}$} & \multicolumn{2}{|c|}{$\begin{array}{l}\text { Crim Justice } \\
\quad(n=112)\end{array}$} & \multicolumn{2}{|c|}{$\begin{array}{l}\text { Psychology } \\
(n=171)\end{array}$} & \multicolumn{2}{|c|}{$\begin{array}{c}\text { Total } \\
(n=429)\end{array}$} \\
\hline & count & $\%$ & count & $\%$ & count & $\%$ & count & $\%$ \\
\hline Use in future career & 118 & 81 & 70 & 63 & 102 & 60 & 290 & 68 \\
\hline Need for graduate school & 88 & 60 & 66 & 59 & 129 & 76 & 283 & 66 \\
\hline Professor & 23 & 16 & 21 & 19 & 24 & 14 & 68 & 16 \\
\hline Like math & 21 & 14 & 13 & 12 & 21 & 12 & 55 & 13 \\
\hline Challenging course & 11 & 8 & 7 & 6 & 12 & 7 & 30 & 7 \\
\hline
\end{tabular}

Business Statistics are very important for me to understand because I plan on going into major: management and I am going to have to use statistics to make decisions and I need to know what they mean. I am pretty good at math so I don't mind the class and I think that the better I get at it, the more competitive I will be and the more successful I will be. After a few years of work experience, I am going to get my MBA so I think it will help to have a stats background as well. (Coded as use in future career, like math, and need for graduate school.)

Business Business is all about numbers so you have to know about statistics. I will be able major: to do the basic procedures but I am hoping other people will be doing that. More importantly, I will be able to interpret the outputs and ask the right questions so that the right analyses can be done then I can use that to help in understanding what is going on. I have to know statistics for the field I am going in and I don't know if I will have to deal with it on a daily basis, but definitely on a routine basis. I am also decent at math which makes it easier for me than most others and that will be an advantage in getting a job and keeping it. (Coded as use in future career and like math.)

Criminal I like statistics because I am good at it since it is a math course and I am good at math. Justice It is a different type of math class because it is just not the numbers, but also different major: concepts that you have to connect it with so I actually like the challenge of trying to understand it. The professor does a good job at giving good examples and explaining things although he often goes too slow. (Coded as like math, challenging course, and professor.)

Criminal I was not sure what exactly to expect when I took this course but it is not as bad as Justice people say it is as long as you keep up. I am going to work for a couple years then go major: back for my masters and the place I want to go is pretty heavy into research so I have to know how to do statistics. (Coded as need for graduate school.)

Psychology I feel that statistics is a very important class. I have already taken classes that talked major: about statistics before I took this class and was lost, but now it makes it so much 
better. I am definitely going to grad school and I am going to have to do research so I have to know what I am doing so I can get in and do statistics when I get there. I want to work with children in a school so statistics will be important because of all the tests I will be giving and I have to know what I am doing. (Coded as use in future career and need for graduate school.)

Psychology My professor told me that stats are tools that you can use to figure out problems and I major: like to think of it that way. I like figuring out problems and statistics is used to do that for the problems that interest me. I do find the course to be tough but I like that. As a psychology major, I have to go to graduate school and most programs require at least two research courses so I want to be prepared for it. (Coded as challenging course and need for graduate school.)

\subsection{NEGATIVE ATTITUDE CATEGORIES}

Approximately three out of eight students $(n=255)$ across majors had a negative attitude toward statistics. For those students with a negative attitude, the qualitative data analysis yielded five categories of responses. The response categories across majors in descending order included: difficulty, nonuse in future career, dislike math, not part of the major, and professor. See Table 3 for the frequencies and percentages of responses by major. It should be noted that participants could have indicated several categories within a question, thus the frequencies add up to more than the sample size and percentages to more than $100 \%$. Based on the categorizations, it can be seen that there is considerable overlap between the positive and negative categories. A series of five chi-square tests, one for each category, were conducted to determine whether there was a relationship between major and the category. A Bonferroni correction was used to account for the multiple chi-square tests. The analyses yielded a significant finding for nonuse in future career across majors $\left(\chi^{2}(2, n=190)=\right.$ $35.64, p<.01)$. After using the Bonferroni correction to examine the three comparisons, there were fewer responses among business majors compared to students from criminal justice $(z=4.37, p<$ $.017)$ and psychology $(z=5.64, p<.017)$. Similar to the finding with positive attitudes, students in criminal justice and psychology with a negative attitude may have careers in mind that are more in line with direct services and they may have not made the connection of how statistics may be used in the field they intend to pursue, whereas business majors may have more of an understanding of applications of statistics in business. As with the reasons associated with positive attitudes, many responses contained several categories. The following are some examples across majors.

Table 3. Frequencies and percentages of responses for those with a negative attitude toward statistics by major

\begin{tabular}{lcccccccc}
\hline Category & \multicolumn{7}{c}{ Major } \\
\cline { 2 - 9 } & \multicolumn{2}{c}{$\begin{array}{c}\text { Business } \\
(n=61)\end{array}$} & \multicolumn{2}{c}{ Crim Justice } & \multicolumn{2}{c}{ Psychology } & \multicolumn{2}{c}{ Total } \\
& count & $\%=84)$ & count & $\%$ & count & $\%$ & count & $\%$ \\
\hline Difficulty & 54 & 89 & 74 & 88 & 99 & 90 & 227 & 89 \\
Nonuse in future Career & 28 & 46 & 67 & 80 & 95 & 86 & 190 & 75 \\
Dislike math & 37 & 61 & 62 & 74 & 79 & 72 & 178 & 70 \\
Not related to major & 9 & 15 & 17 & 20 & 18 & 16 & 44 & 17 \\
Professor & 10 & 16 & 8 & 10 & 16 & 15 & 34 & 13 \\
\hline
\end{tabular}

Business major: $\quad$ I am OK with math but this is not really math and it is so difficult. Honestly, I am not sure that I will be using it very much in my job so I think it is a waste of a class and money. I would like to know who the genius was that decided I have to take this class to run a company. If I need to do statistics, I'll hire somebody. (Coded as difficulty and nonuse in future career.)

Business major: Math has never been something I enjoy or have been good at. Although I am a business major, I am going into HR so I am going to be making employment decisions and not doing statistics all day long. I honestly do not know how I 
will use any of this in the job I hope to get. Rather than helping, the professor makes the tests so hard so no matter how hard I try I don't get it. (Coded as dislike math, nonuse in future career, and professor.)

Criminal Justice I do think this is the hardest criminal justice class. I know for sure that I am not major: going to use any of this stuff when I graduate so I have no idea why I have to take it. I think it should be an elective so if you want to learn this stuff you can but it should not be forced on you because I do not think it is very important for my major. (Coded as difficulty, nonuse in future career, and not related to major.)

Criminal Justice Give me a break, I am going to be a cop. What in the world does a cop need to major: know about statistics? The answer is nothing. The only thing I need to know is that if my job makes me do statistics, I need to get another job. The reason I am going to be a cop is so I don't have to deal with math. (Coded as nonuse in future career and dislike math.)

Psychology This class is a total waste of my time and I can't believe I have to take two major: courses in it. When am I going to have to figure out some formula when I am a counselor or do something on SPSS? I became a psychology major so I didn't have to take math courses and I actually did OK in math but this is different as it is much more difficult and frustrating. I do not feel it should be a required course when studying for a bachelor's degree and think they need to change the curriculum. I suppose that it is important for those that want to go into research but most of us don't want to do that so I don't understand why we have to take it. (Coded as difficulty, dislike math, nonuse in future career, and not related to major.)

Psychology I believe it is pointless. I am never going to use it after this class. So, I am being major: forced to do things to get a psychology degree and learn statistics for two semesters which is the hardest class then never use it again. At least I will use other stuff from other classes. If I need to do stats at my job, I'll hire someone for that so it is in no way important for the field I am going in to. (Coded as difficulty and nonuse in future career.)

\section{DISCUSSION}

The present study examined the responses of 684 undergraduate majors from business, criminal justice, and psychology, and then developed categories based on qualitative methodologies. The initial question answered by participants perhaps captured a domain similar to affect as measured on the SATS (Schau et al., 1995). There is a shortcoming to point out regarding the general attitude assessment used in this manner. That is, it was a single item indicator which calls into question the reliability of the measure. However, it was found that approximately $60 \%$ of students indicated a positive attitude toward statistics which is similar to prior findings (e.g., Mills, 2004; Waters, Zakrajsek, \& Popovich,1989). The question was intentionally provided in a manner in which the student was unable to select a neutral position as the research objective was to separate students on the basis of a general positive or negative attitude and to assess the categories that emerged from each group.

The analysis yielded five categories for both positive and negative attitudes which did provide corroboration for many of the domains found on the SATS. See Table 4 for a comparison of categories from the present study and the SATS. For those with a positive attitude, the categories use in future career and need for graduate school were similar to the SATS domain of value, liking math was similar to cognitive competence, and challenging course was similar to difficulty. For those with a negative attitude, the category of difficulty was similar to the SATS domain of difficulty, nonuse in future career and not related to major were similar to value, and disliking math was similar to cognitive competence. Affect as well as the two most recent additional domains to the SATS (i.e., interest and effort) were not represented categories based on the responses from this sample. One domain from this analysis that was identified for students with both positive and negative attitudes was the professor. Many characteristics of the instructor can perhaps influence the attitudes of 
students and should be considered in current scales. In other words, some professors may attempt to reduce fear at the beginning of the semester as recommended by Blalock (1987), whereas others may instill fear and anxiety by stressing the difficulty of the course and past rates of failure in the course. In both cases, the instructor certainly has the potential to influence student attitudes based on the approach. It may be the case that the professor dimension is distinct from teaching style and may represent student perceptions of the instructor's attitude.

Table 4. Comparison between domains derived from the qualitative analysis and the SATS

\begin{tabular}{ll}
\hline Qualitative Analysis Domain & SATS Domain \\
\hline Use in future career (+), need for graduate school (+), & Value \\
nonuse in future career (-), not related to major (-) & Difficulty \\
Challenging course (+), difficulty (-) & Cognitive competence \\
Like math (+), dislike math (-) & None \\
Professor (+), professor $(-)$ & Interest \\
None & Effort \\
None & \\
\hline
\end{tabular}

The results of this study can be used by instructors to tailor course delivery in order to better engage students in statistics classes. Specifically, across both positive and negative attitudes, the categories of use and nonuse in future careers, need for graduate school, and not related to the major, are all dimensions that instructors can easily address in class. Besides the obvious need for instructors to teach the actual subject matter of statistics, it may be important to have repeated discussions on why statistics should be learned, how it is relevant to their careers, how it is important in their chosen major, and what expectations in graduate schools may be. More business students had a better understanding of the importance of statistics in their future careers. Based on the responses, this may be related to examples that are used in class. For example, students in business might use sales data to illustrate a point or perhaps perform analyses and offer interpretations. The majority of business majors may be able to relate to that data because most will be involved with sales numbers or profit/loss in some capacity. Psychology, as an example, may provide a different approach. The majority of undergraduate psychology majors are typically interested in direct services which are often in the areas of clinical psychology or counseling. The majority of psychology professors who teach statistics are most likely from non-clinical backgrounds such as experimental, cognitive, or developmental psychology, to name a few. It may be the case that the examples used by those professors may be specific to their interest area rather than the interests of the students. The majority of criminal justice majors may also pursue careers that are more service oriented. As such, they may perceive their future employment in areas of probation, parole, prisons, juvenile justice, and others, as fields that will not require them to be users or consumers of statistics to a large extent. One approach might be to determine the intended career plans of students and provide examples that are applicable in those settings. Regardless of how this is to be accomplished, instructors of psychology and criminal justice certainly have improvements to make in order to provide students more information on how statistics will be relevant to their future careers.

Although this study provided some useful findings, there are several limitations that should be discussed. First, participants were forced to choose either a positive or negative attitude. Attitudes toward statistics are probably not best measured on a dichotomized scale and may very well be on a continuum. Furthermore, it may be possible that students may have both positive and negative attitudes toward statistics, which is a reason to use standardized assessments (e.g., SATS) that can better dissect those attitudes on various dimensions. It may also be possible that participants were fairly ambivalent or neutral toward statistics. A neutral category was not provided because the purpose of the current study was to force participants into choosing their overall attitude in a dichotomized manner, then develop categories for students with positive affect and for those with negative affect, and finally examine the degree of overlap. There were five dimensions for both the positive and negative attitudes and examination of those shows that four were similar. Specifically, the positive-negative parings that were similar included future career-nonuse in future career, 
professor-professor, like math-dislike math, and challenging course-difficulty. Because each pairing seems to be measuring the same construct, it certainly lends support that a more sophisticated scale may be a better alternative in measuring those domains rather than a dichotomized approach. A second limitation is that the textbook was not a consideration. It may be the case that business majors used a textbook that featured business-oriented examples and exercises, whereas psychology and criminal justice majors may have used a more general textbook that was not discipline specific. A third limitation is that only two universities across three disciplines were used, thus generalizations should be made with caution. It is possible that the professor category may have been influenced by a particularly good or bad professor at one of the universities. The importance of the professor domain may be quite different at other universities as the current study examined responses from students taking classes from six different professors.

There are several directions in which future research could use the findings of this study. One direction would be to offer a neutral category for the initial question regarding students' general attitudes toward statistics as that group may represent a different set of responses. A more refined method of accomplishing this task would be to use a standardized subscale like the affect domain on the SATS to create groups based on the distribution of the sample. The affect domain is a six-item subscale designed to assess students' positive and negative feelings about statistics. Using the subscale would allow any number of comparisons based on categorizations of the affect subscale scores. This would certainly offer a more precise manner in which to measure the affect dimension or overall feeling about statistics. Another interesting investigation might use a similar methodology but target a particular major and the department that delivers the course. The data suggest that the professor was mentioned as a factor contributing to both positive and negative attitudes. There are typically two ways in which students in most non-mathematics majors take a statistics course. That is, they often take a statistics course in their department offered by the departmental methodologist or they may take it in a department of mathematics or statistics which is often taught by a statistician. Which is most useful for students? Statisticians may make the argument that they are experts in statistics so they should be teaching the statistics courses. Non-mathematical departments may make the argument that students are better served by their instructors because they can better provide pertinent examples and applications that are specific to their field of study. A study of this nature would provide evidence to answer this question that has been discussed on campuses for decades. Lastly, statistics is a required course for many majors beyond business, criminal justice, and psychology. Thus, it may be worthwhile to examine other majors across a more representative number of different universities. Lastly, another avenue that might provide useful information is to use a similar methodological approach as this study, but in a pre-post manner such that students are assessed at the beginning of the course and after completing the course. This approach would provide insight into the degree that certain dimensions of both positive and negative attitudes toward statistics may be subject to change during a course which certainly may vary by discipline.

\section{REFERENCES}

Aiken, L. R. (1970). Attitudes toward mathematics. Review of Educational Research, 40(4), 551-596.

Aiken, L. R. (1976). Update on attitudes and other affective variables in learning mathematics. Review of Educational Research, 46(2), 293-311.

Aiken, L. R., \& Dreger, R. M. (1961). The effect of attitudes on performance in mathematics. Journal of Educational Psychology, 52(1), 19-24.

Atkinson, J. W. (1957). Motivational determinants of risk-taking behaviors. Psychological Review, 64(6), 359-372.

Bandura, A. (1977). Social learning theory. Englewood Cliffs, NJ: Prentice Hall.

Blalock, H. M. (1987). Some general goals in teaching statistics. Teaching Sociology, 15(2), 164-172.

Coetzee, S, \& van der Merwe, P. (2010). Industrial psychology students' attitudes toward statistics. South African Journal of Industrial Psychology, 36(1), 1-8.

Derry, S. J., Levin, J. R., Osana, H. P., Jones, M. S., \& Peterson, M. (2000). Fostering students' statistical and scientific thinking: Lessons learned from an innovative college course. American Educational Research Journal, 37(3), 747-773. 
Dunn, D. S. (2000). Letter exchanges on statistics and research methods: Writing, responding, and learning. Teaching of Psychology, 27, 128-130.

Elmore, P. B., \& Vasu, E. S. (1980). Relationships between selected variables and statistics achievement: Building a theoretical model. Journal of Educational Psychology, 72(4), 457-467.

Elmore, P. B., \& Vasu, E. S. (1986). A model of statistics achievement using spatial ability, feminist attitudes and mathematics-related variables as predictors. Educational and Psychological Measurement, 46(1), 215-222.

Feinberg, L. B., \& Halperin, S. (1978). Affective and cognitive correlates of course performance in introductory statistics. Journal of Experimental Education, 46(4), 11-18.

Gal, I., Ginsburg, L., \& Schau, C. (1997). Monitoring attitudes and beliefs in statistics education. In I. Gal \& J. B. Garfield (Eds.), The assessment challenge in statistics education (pp. 37-51). Amsterdam: IOS Press.

Garfield, J., \& Ben-Zvi, D. (2007). How students learn statistics revisited: A current review of research on teaching and learning statistics. International Statistical Review, 75(3), 372-396.

Guba, E. G., \& Lincoln, Y. S. (1989). Fourth generation evaluation. Thousand Oaks, CA: Sage Publications.

Harlow, L. L., Burkholder, G. J., \& Morrow, J. A. (2002). Evaluating attitudes, skill, and performance in a learning-enhanced quantitative methods course: A structural modeling approach. Structural Equation Modeling, 9, 413-430.

Hill, C. E., Thompson, B. J., \& Williams, E. N. (1997). A guide to conducting consensual qualitative research. The Counseling Psychologist, 25(4), 517-572.

Hilton, S. C., Schau, C., \& Olsen, J. A. (2004). Survey of Attitudes Toward Statistics: Factor structure invariance by gender and by administration time. Structural Equation Modeling, 11(1), 92-109.

Laher, S., Israel, N., \& Pitman, M. (2007). Teaching research and statistics at undergraduate level: The RDA tutorial programme. South African Journal of Psychology, 37(2), 368-374.

Maehr, M. (1984). Meaning and motivation: Toward a theory of personal investment. In R. Ames \& C. Ames (Eds.), Research on motivation in education, Vol. 1: Student motivation (pp. 115-144). Orlando, FL: Academic.

Mij, A. (2009). Differences in university students' attitudes and anxiety about statistics. Psychological Reports, 104(3), 737-744.

Miles, M. B., \& Huberman, M. A. (1994). Qualitative data analysis: An expanded sourcebook (2nd ed.). Thousand Oaks, CA: Sage Publications.

Mills, J. D. (2004). Students' attitudes toward statistics: Implications for the future. College Student Journal, 38(3), 349-361.

Morrow, S. L., \& Smith, M. L. (2000). Qualitative research for counseling psychology. In S. D. Brown \& R. W. Lent (Eds.), Handbook of counseling psychology (3rd ed., pp. 199-230). Hoboken, NJ: John Wiley \& Sons.

Mulhern, G., \& Wylie, J. (2004). Changing levels of numeracy and other core mathematical skills among psychology undergraduates between 1992 and 2002. British Journal of Psychology, 95(3), 355-370.

Onwuegbuzie, A. J. (2000). Attitude toward statistics assessments. Assessment and Evaluation in Higher Education, 25(4), 321-339.

Onwuegbuzie, A. J., \& Seaman, M. A. (1995). The effect of time constraints and statistics text anxiety on test performance in a statistics course. Journal of Experimental Education, 63, 115-124.

Patton, M. Q. (1990). Qualitative evaluation and research methods (2nd ed.). Thousand Oaks, CA: Sage Publications.

Ridgway, J., Nicholson, J., \& McCusker, S. (2007). Teaching statistics - Despite its applications. Teaching Statistics, 29(2), 44-48.

Roberts, D. M., \& Bilderback, E. W. (1980). Reliability and validity of a statistics attitude survey. Educational and Psychological Measurement, 40(1), 235-238.

Schau, C. (1992). Survey of Attitudes Toward Statistics (SATS-28).

[Online: http://evaluationandstatistics.com/]

Schau, C. (2003). Survey of Attitudes Toward Statistics (SATS-36).

[Online: http://evaluationandstatistics.com/] 
Schau, C., Stevens, J., Dauphinee, T. L., \& Del Vecchio, A. (1995). The development and validation of the Survey of Attitudes Toward Statistics. Educational and Psychological Measurement, 55(5), $868-875$.

Schram, C. M. (1996). A meta-analysis of gender differences in applied statistics achievement. Journal of Educational and Behavioral Statistics, 21(1), 55-70.

Schutz, P. A., Drogosz, L. M., White, V. E., \& Distefano, C. (1998). Prior knowledge, attitude, and strategy use in an introduction to statistics course. Learning and Individual Differences, 10(4), 291-308.

[Online: http://dx.doi.org/10.1016/S1041-6080\%2899\%2980124-1]

Strauss, A., \& Corbin, J. (1998). Basics of qualitative research techniques and procedures for developing grounded theory (2nd ed.). London: Sage Publications.

Tempelaar, D. T., Van Der Loeff, S. S., \& Gijselaers, W. H. (2007). A structural equation model analyzing the relationship of students' attitudes toward statistics, prior reasoning abilities, and course performance. Statistics Education Research Journal, 6(2), 78-102. [Online: http://www.stat.auckland.ac.nz/ iase/serj/SERJ6\%282\%29_Tempelaar.pdf]

Vidich, A., \& Lyman, S. (1994). Qualitative methods: Their research history in sociology and anthropology. In N. Denzin \& Y. Lincoln (Eds.) Handbook of qualitative research (2nd ed., pp. 23 - 59). Thousand Oaks, CA: Sage.

Waters, L. K., Martelli, T. A., Zakrajsek, T., \& Popovich, P. M. (1988). Attitudes toward statistics: An evaluation of multiple measures. Educational and Psychological Measurement, 48(2), 513516.

Waters, L. K., Martelli, T. A., Zakrajsek, T., \& Popovich, P. M. (1989). Measuring attitudes toward statistics in an introductory course on statistics. Psychological Reports, 64(1), 113-114.

Weiner, B. (1979). A theory of motivation for some classroom experiences. Journal of Educational Psychology, 71(1), 3-25.

Wise, S. L. (1985). The development and validation of a scale measuring attitudes toward statistics. Educational and Psychological Measurement, 45(2), 401-405.

JAMES D. GRIFFITH

1857 Old Main Drive

Department of Psychology

Shippensburg University of Pennsylvania

Shippensburg, PA 17257 